\title{
Imaging of firn isochrones across an Antarctic ice rise and implications for patterns of snow accumulation rate
}

\author{
David G. VAughan, ${ }^{1}$ Philip S. ANDERSON,${ }^{1}$ John C. KING, ${ }^{1}$ Graham W. MANN, ${ }^{2}$ \\ Stephen D. MOBBS, ${ }^{2}$ Russell S. LADKIN ${ }^{1}$ \\ ${ }^{1}$ British Antarctic Survey, Natural Environment Research Council, Madingley Road, Cambridge CB3 OET, England \\ E-mail:d.vaughan@bas.ac.uk \\ ${ }^{2}$ School of the Environment, University of Leeds, Leeds LS2 97T, England
}

\begin{abstract}
It has been an underlying assumption in many studies that near-surface layers imaged by ground-penetrating radar (GPR) can be interpreted as depositional markers or isochrones. It has been shown that GPR layers can be approximately reproduced from the measured electrical properties of ice, but these material layers are generally narrower and more closely spaced than can be resolved by typical GPR systems operating in the range 50-400 MHz. Thus GPR layers should be interpreted as interference patterns produced from closely spaced and potentially discontinuous material layers, and should not be assumed to be interpretable as precise markers of isochrones. We present $100 \mathrm{MHz}$ GPR data from Lyddan Ice Rise, Antarctica, in which near-surface $<50 \mathrm{~m}$ deep) layers are clearly imaged. The growth of the undulations in these layers with depth is approximately linear, implying that, rather than resulting from a pattern of vertical strain rate, they do correspond to some pattern of snowfall variation. Furthermore, comparison of the GPR layers with snow-stake measurements suggests that around $80 \%$ of the rms variability in mean annual accumulation is present in the GPR layers. The observations suggest that, at least in this case, the GPR layers do approximate isochrones, and that patterns of snow accumulation over Lyddan Ice Rise are dominated by extremely persistent spatial variations with only a small residual spatial variability. If this condition is shown to be widely applicable it may reduce the period required for measurements of surface elevation change to be taken as significant indications of mass imbalance.
\end{abstract}

\section{INTRODUGTION}

Radio-echo sounding (RES) has been used since the 1960s to image reflecting horizons buried deep in ice sheets (e.g. Robin and others, 1969). These horizons result from dielectric contrasts associated with chemical and crystal fabric changes (Fujita and others, 1999), and several studies have shown some success in simulating the interaction of radar with the dielectric data from ice cores (for a summary, see Miners and others, 2002). In recent years, however, lightweight, easily transportable ground-penetrating radar (GPR) systems have become widely used to image the near-surface ( $<100 \mathrm{~m}$ ) firn (e.g. Arcone and others, 1994, 1995; Delaney and Arcone, 1995; Vaughan and others, 1999). GPR sections collected from such areas typically show a rich architecture of apparent reflectors at approximately the same frequency as the transmitted signal. It has become a widespread assumption that such layers appearing in cold ice result from density variations (cf. Paren and Robin, 1975) that arise during deposition, or post-depositional compaction, and that these layers can be interpreted as depositional isochrones (e.g. Richardson and others, 1997; Richardson and Holmlund, 1999; Vaughan and others, 1999; Frezzotti and others, 2002).

While phase-sensitive systems can achieve much higher resolution (Corr and others, 2002), non-coherent systems, such as commercially available GPR, are limited by wavelength, which is around $0.5-4 \mathrm{~m}$ in firn for the commonly used frequencies 400-50 MHz. Except in areas of excep- tional snow accumulation, such resolution is insufficient to resolve even annual cycles of density change, let alone density change associated with individual precipitation events, which may have a thickness of only a few $\mathrm{cm}$.

Some authors have noted the problem of interpretation of GPR layers, but argued that the superposed reflections from two or more density contrasts separated by less than the wavelength would result in the GPR layers being isochrones (e.g. Palli and others, 2002). In a recent study, Eisen and others (2003) showed that the mean GPR trace collected from a common-midpoint stack could be modelled successfully using a forward modelling technique applied to $\log$ s of d.c. conductivity and a.c. permittivity measured from an ice core taken from the common midpoint. The modelling is strikingly successful in reproducing the GPR data, but shows quite clearly that there is no simple correspondence between the electrical logs and the GPR layers. Indeed, Eisen and others show that the GPR layers are interference patterns resulting from echoes from many narrow permittivity contrasts within the ice (cf. the interpretation of deep RES data; Harrison, 1973). Eisen and others do not, however, show that these permittivity contrasts are sufficiently spatially continuous to imply that they can be tracked over significant horizontal distances, or that the interference pattern is sufficiently stable, with respect to the likely variations in the spacing of the permittivity contrasts, to be locked to particular isochronous material layers. In summary, although Eisen and others (2003) have made a very significant advance in 


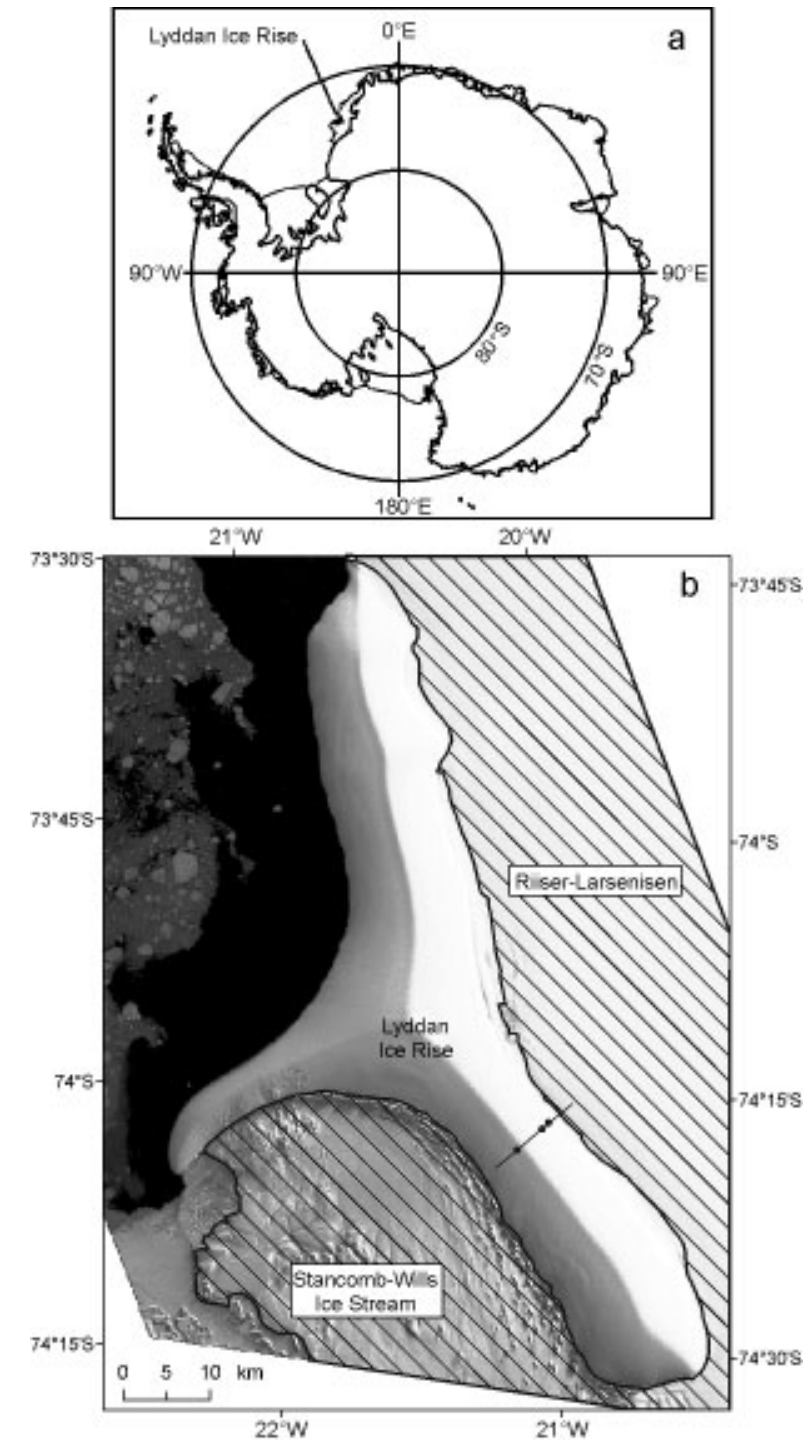

Fig. 1. (a) Location of Lyddan Ice Rise, Antarctica. (b) Landsat-7 Enhanced Thematic Mapper (ETM) image of Lyddan Ice Rise $(10 \mathrm{~m}$ resolution panchromatic sub-scene from image path/row 184/112, 4 January 2000). The portion of floating ice shelf covered by the image is hatched.

understanding the process of the formation of GPR layers, their study cannot be taken as proof that GPR layers are universally interpretable as isochrones.

There is, of course, some direct observational evidence that GPR layers do approximate isochrones. For example, GPR sections have been acquired between dated ice cores, showing that GPR layers intersect adjacent ice cores at around the same date (e.g. Palli and others, 2002; Richardson-Naslund, 2004). However, such high-quality data are sparse, and in the absence of an understanding of the physical process, we believe that the assumption that GPR layers are isochrones requires further testing. Here we present further observational evidence that there is a persistent spatial pattern in mean net surface mass balance over horizontal distances of $1 \mathrm{~km}$ that can explain the architecture of the GPR layers sufficiently to interpret them as, at least approximately, isochrones.

\section{DATA GOLLEGTION}

We collected data on a transect across Lyddan Ice Rise, Antarctica $\left(74^{\circ} \mathrm{S}, 22^{\circ} \mathrm{W}\right.$; Fig. 1), between January 2000 and
February 2002. The crest of Lyddan Ice Rise stands $130 \mathrm{~m}$ above the surrounding ice shelf, and mean slopes on its flanks are $\sim 2.5 \%$. The mean annual temperature is $19.9^{\circ} \mathrm{C}$, and summer melting is probably a very rare occurrence: in one year of automatic weather station observations, only 11 hours were recorded where the air temperature exceeded $0^{\circ} \mathrm{C}$.

\subsection{GPR}

Our GPR data were collected using a Pulse Ekko 100 system, operating at $100 \mathrm{MHz}$ (wavelength $\sim 2 \mathrm{~m}$ in firn; Fig. 2e), with position determined using a dual-frequency kinematic global positioning system (GPS). This radar system has been widely used to image the near-surface structure in ice sheets, and operating at $100 \mathrm{MHz}$ is capable of imaging layers to 50-100 $\mathrm{m}$ depth (Vaughan and others, 1999; Nath and Vaughan, 2003). We used standard processing techniques similar to those described by Woodward and others (2003) to convert two-way travel time to depth. We used a velocity of $200 \mathrm{~m} \mu \mathrm{s}^{-1}$, which, we determined from common-midpoint experiments, is a reasonable value for firn in a similar setting of mean annual temperature and accumulation rate (Nath and Vaughan, 2000).

The likely errors in the GPR data comprise uncertainties in the positioning of the radar system, the limitations that arise from the imaging technique and limitations in the radar system itself. Of these sources, uncertainty in the positioning is of little concern as the sub-metre precision of the GPS solution is sufficient for our uses. Similarly, the distortion of the layers due to the imaging technique, i.e. the migration of the layers away from their true position as a result of off-nadir reflections, is not significant in this case because the slopes of the layers away from the surface are very low $\left(<1^{\circ}\right)$. The practical resolution of the radar system operating at $100 \mathrm{MHz}$ has been discussed above, and we assume other biases introduced by the radar system are constant across the transect. Thus the major uncertainty in the GPR data is that arising because the snow-surface reflection is not visible in the GPR section. This happens because at this point in the receive cycle the system is still saturated by the pulse that passes directly through the air between the antennae. This implies the zero-depth datum chosen in Figure $2 \mathrm{e}$ has an uncertainty of several metres. In practical terms, this has little significance except that it could explain why the regression lines drawn in Figure 3 (discussed in section 3.1) converge about $3 \mathrm{~m}$ below the nominal zero depth

\subsection{Snow-stake and density measurements}

InJanuary 2000, we planted 30 snow stakes (25 mm external diameter closed aluminium tubes) at $\sim 500 \mathrm{~m}$ intervals along the transect. The snow stakes were revisited and the change in exposed length was measured in January 2001 and again in January 2002. During the visit in 2001, density profiles were measured at 26 of the stakes using samples taken from the walls of snow pits and from shallow ice cores (Fig. 2c). The net snow accumulation rate was calculated for both years (2000 and 2001), assuming that the density profiles measured in 2001 are appropriate for both years (Fig. 2d).

\section{DISGUSSION OF DATA}

Our GPR data were collected assuming a wavelength of 

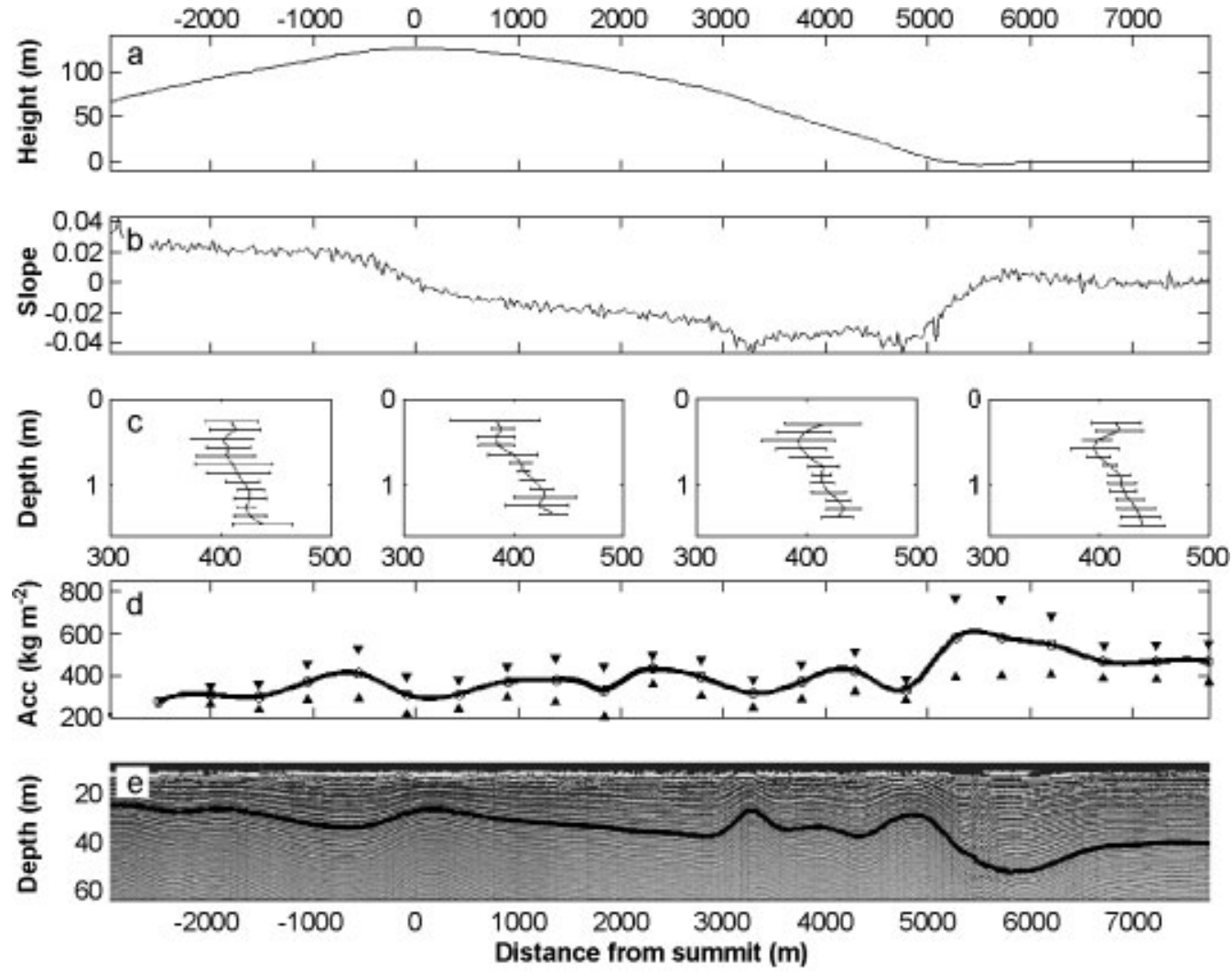

Fig. 2. The data collected along the transect across Lyddan Ice Rise. Distances in this and subsequent figures are given relative to the summit of the ice rise, with distances east of the summit taken as positive. (a) Surface height measured using kinematic GPS, relative to the World Geodetic System 1984 (WGS84) ellipsoid. The approximate interval between successive points is $30 \mathrm{~m}$. (b) Surface slope calculated using height data in (a). The slopes were calculated over three points. (c) Density data. Each frame represents five separate ice cores/density pits collected at successive stakes. The mean density $\left(\mathrm{kg} \mathrm{m}^{-3}\right)$ and standard deviation between the five pits are given at $10 \mathrm{~cm}$ intervals of depth. (d) Accumulation measurements from snow stakes, shown for both years January 2000-Fanuary 2001 ( $\mathbf{\text { ) }}$ and January 2001-January 2002 ( $\boldsymbol{\nabla}$ ). The mean accumulation over both years is also shown ( $\bigcirc$ ), with points joined by a cubic spline. (e) $100 \mathrm{MHz}$ GPR section. Depths have been calculated from the two-way travel time using a mean speed for radio waves in ice of time using $200 \mathrm{~m} \mathrm{~ms}^{-1}$. One GPR layer has been highlighted, to allow easy comparison with accumulation data in $(d)$.

$\sim 2 \mathrm{~m}$ in firn. Averaged over the two years, the mean annual accumulation at this site was $0.95 \mathrm{~m}$ of snow. Thus each light-dark cycle in the GPR section represents roughly 2 years of accumulation, and it is clear that the GPR data do not 'resolve' individual annual layers of snow.

Furthermore, while there may be a strong annual cycle in density, driven by strong summer melting, which can be directly resolved in radar data in other areas (e.g. Kohler and others, 1997), our density core/pit data showed no strong seasonal changes. The density measurements at similar depths at nearby sites showed greater variation than was visible down each core/pit (Fig. 2c).

\subsection{Burial features}

Our GPR section shows layers to at least $50 \mathrm{~m}$ depth, with a rich architecture of arches and troughs similar to those seen in earlier studies. Although the analysis could apply to either bumps or troughs, we have analyzed only the noticeable bumps in the GPR section, to determine their likely origin. Figure 3 shows that when plotted against ice equivalent depth each bump grows in a linear manner down the section, and their apparent origin is close to the present surface (see section 2.1). Vaughan and others (1999) argued that this

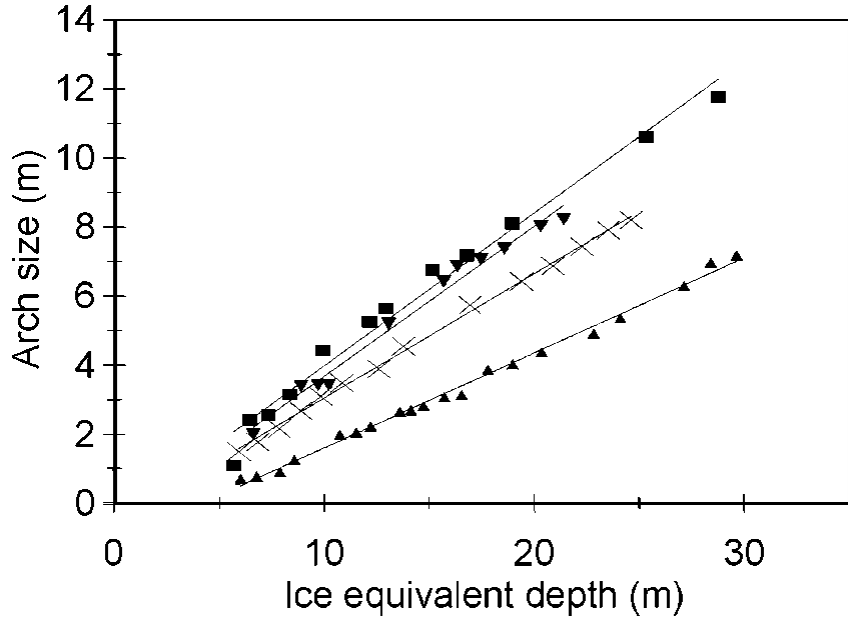

Fig. 3. Growth of arches in GPR layers as a function of ice equivalent depth for four arches in the GPR layers visible in Figure $2 e,-2000 m$ ( $\mathbf{\Delta}),+150 m(\times),+3200 m$ ( $)$ and $+4800 \mathrm{~m}$ ( $)$. The size and depth of the features has been converted from two-way travel time to ice equivalent depth using a standard velocity-depth function (Nath and Vaughan, 2003). The burial of each arch is well described by a straight line, which emanates from the same point with a depth around zero, showing that these features are consistent with an origin as a feature arising from a persistent spatial perturbation in surface accumulation rate. 


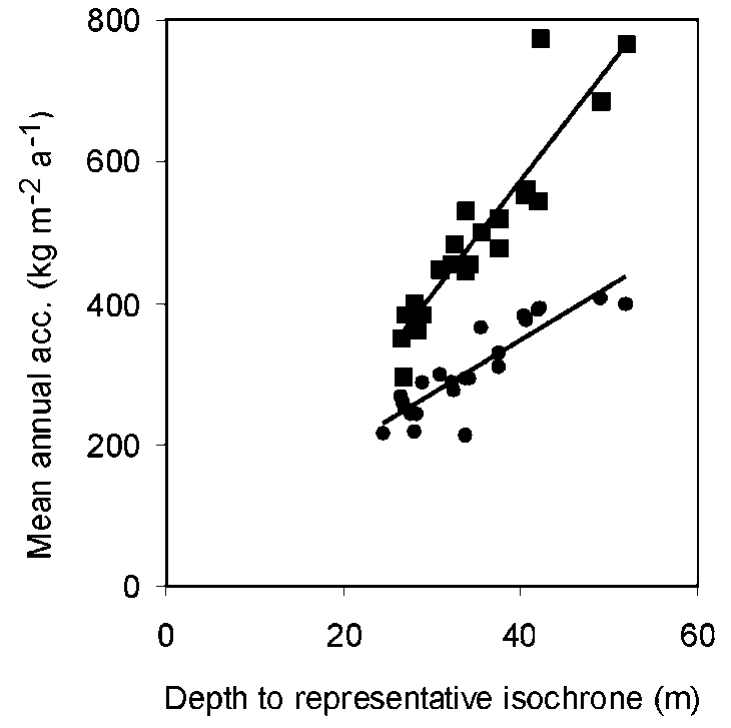

Fig. 4. Comparison of the depth of the representative isochrone highlighted in Figure $2 e$ with snow-stake measurements of mean annual snow accumulation for 2000/01 (•; $\left.r^{2}=0.78\right)$ and $2001 / 02\left(\boldsymbol{\square} ; r^{2}=0.86\right)$.

linear growth is only compatible with features that are created by a persistent spatial pattern of surface accumulation, and is not compatible with features caused by strain-rate variations which grow quadratically with depth. It is notable that even the arch near the summit $(+200 \mathrm{~m})$ appears to grow linearly with depth, and so cannot have the same origin as the Raymond bump feature identified on Fletcher Promontory, Antarctica (Vaughan and others, 1999). It is more likely that this arch is caused by localized scouring close to the summit, as described by Fisher and others (1983).

\subsection{Correlation of GPR layers and mean net surface accumulation}

The snow-stake data (Fig. 2d) show a different mean accumulation rate during the two years $\left(305 \mathrm{~kg} \mathrm{~m}^{-2} \mathrm{a}^{-1}\right.$ in 2000/ $01 ; 490 \mathrm{~kg} \mathrm{~m}^{-2} \mathrm{a}^{-1}$ in 2001/02), with high deviations around the mean ( \pm 68 and $\pm 125 \mathrm{~kg} \mathrm{~m}^{-2} \mathrm{a}^{-1}$, respectively). However, the pattern of spatial variation for each year is broadly similar (Fig. 2d), with significantly higher accumulation on the eastern side. We will discuss the relationship of snow accumulation and the climatic winds elsewhere (King and others, 2004), but this is climatically the windward side of the ice rise.

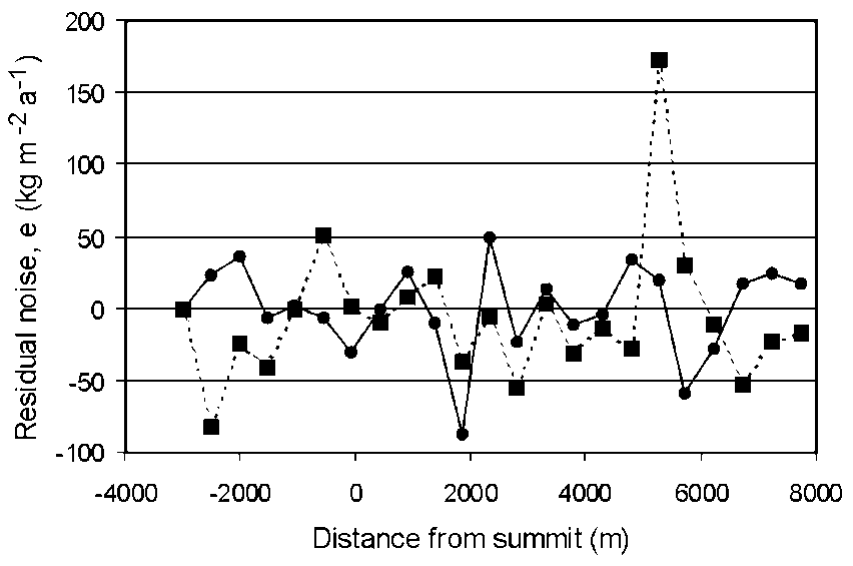

Fig. 5. Residual noise in mean annual accumulation rate, $e\left(\underline{x}, t_{i}\right)$, for 2000/01 (solid circles) and 2001/02 (solid squares).

It is clear that in broad terms the spatial variation measured in the snow-stake data is reflected in the GPR layers; quantitatively, the correlations in Figure 4 suggest that $\sim 80 \%$ of the spatial variation in annual snow accumulation in a single year is present in the GPR layers. This is strong evidence that the GPR layers at least approximately represent isochrones, although the reliability of this approximation cannot be assessed further with these data: more data of the type collected by Palli and others (2002), i.e. dated cores intersecting GPR data, will be required to determine the precision of the approximation.

\subsection{A model for variations in snow accumulation}

If we accept the preceding argument that the GPR layers can be taken as approximate isochrones, and indicate the persistent spatial variations in snow accumulation, then we can suggest a particular model to describe the spatial and temporal variations of snow accumulation on Lyddan Ice Rise. We suggest that the spatial and temporal variation of mean annual snow accumulation at a particular point on Lyddan Ice Rise, $a\left(\underline{x}, t_{i}\right)$, is well represented by the following decomposition:

$$
a\left(x, t_{i}\right)=a_{0}\left(t_{i}\right) a(\underline{x})+e\left(x, t_{i}\right),
$$

where $a_{0}\left(t_{i}\right)$ represents the regional mean accumulation for the year $i$. This regional mean accumulation is modified locally by the persistent spatial variation, $a(\underline{x})$, and a nonpersistent residual component, $e\left(\underline{x}, t_{i}\right)$.

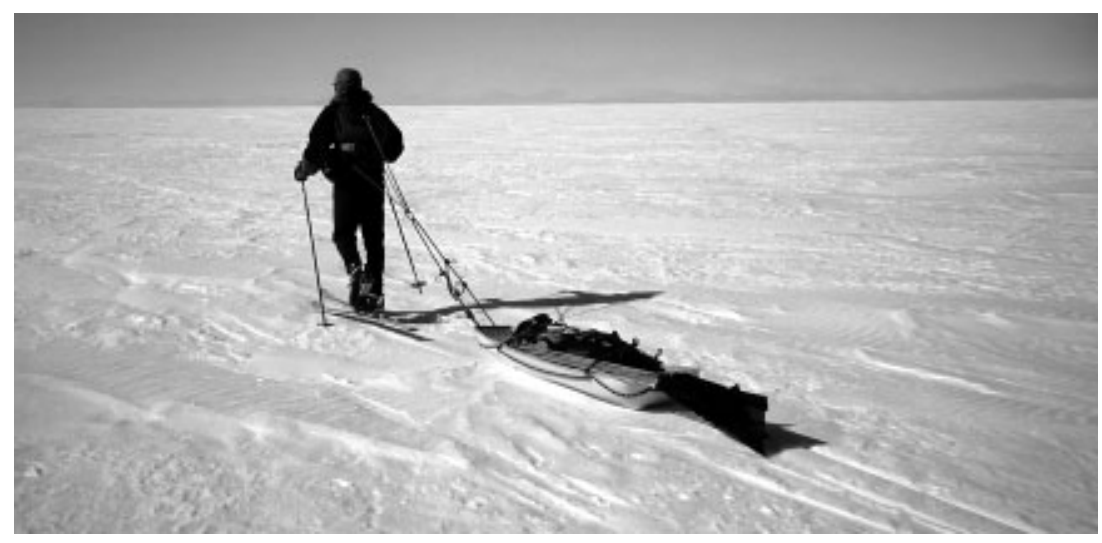

Fig. 6. Photograph of the snow conditions during the 2002 resurvey of Lyddan Ice Rise. Note the sastrugi with amplitude of a few centimetres covering the snow surface. 
If we assume that the relative depths to the representative GPR layer give the dimensionless values for the persistent spatial variation, $a(\underline{x})$, and that the point-wise mean of the snow-stake measurements gives the regional mean for the particular years, $a_{0}\left(t_{i}\right)$, then the residual accumulation may easily be calculated for each of the years of observation (Fig. 5). We find that this residual variability is generally small, having root-mean-square (rms) amplitude of 30 and $49 \mathrm{~kg} \mathrm{~m}^{-2} \mathrm{a}^{-1}$ for 2000/01 and 2001/02 respectively. Furthermore, the residual variability is uncorrelated between the years $\left(r^{2}<0.001\right)$, and any spatial structure it might contain must be under-sampled by the $500 \mathrm{~m}$ stake spacing. We note that these rms amplitudes are equivalent to $7-12 \mathrm{~cm}$ of snow at surface density; this is probably a little larger than the amplitude of the short-wavelength sastrugi observed on Lyddan Ice Rise during the surveys (see Fig. 6). We conclude that the residual variability cannot be simply ascribed to sastrugi, but is probably due to minor differences in wind climate affecting the wind-borne redistribution of snow.

\section{CONGLUSIONS}

Although we have argued that the interference patterns seen by GPR systems operating over cold ice cannot, a priori, be assumed to follow isochronous layers of snow deposition, we have presented observational data that this is indeed the case. We have shown that on Lyddan Ice Rise the growth of bumps in the GPR layers with depth, and the high correlation of GPR layer depth with in situ measurements of snow surface accumulation, support the hypothesis that the GPR layers are, at least approximately, isochrones.

Accepting that the GPR layers approximately represent isochrones allows the use of GPR across a range of studies. It supports the results of earlier studies investigating snow accumulation patterns (e.g. Richardson and others, 1997; Richardson and Holmlund, 1999) and will provide a simple tool with which to investigate the spatial patterns of accumulation-rate variations.

In this case, using a representative GPR layer as an indication of the persistent spatial variations in snow accumulation suggests a particular model of spatial and temporal variations in snow accumulation for Lyddan Ice Rise. This model suggests that $80 \%$ of the spatial variation in a single year is persistent from year to year, and that the non-persistent component is a little larger in amplitude than sastrugi on the snow surface and has a spatial wavelength too short to be sampled by our stakes (spaced at $\sim 500 \mathrm{~m}$ ).

The form of this model is more constraining than the general case, in which all the variations in snow accumulation would be spatially and temporally random, and it has implications for the interpretation of changes in surface elevation. For example, a simple observation of the total variability in mean annual accumulation, i.e. all our snowstake measurements taken together, might suggest an rms variability of $\pm 134 \mathrm{~kg} \mathrm{~m}^{-2} \mathrm{a}^{-1}( \pm 32 \mathrm{~cm}$ of snow $)$. Our model, however, suggests that the temporal variability is much smaller than this, which substantially reduces the time required to achieve significance, although to calculate this precisely would require a measure of the temporal variability of the accumulation rate at a point, which is not available for Lyddan Ice Rise.

To completely characterize the accumulation variations, even in this apparently simple area, would require measure- ments of each of the parameters in the model: the interannual variability at a point, which must be determined from a well-dated ice core or pit; the persistent spatial variation, which can probably best be derived from GPR layers; and the residual spatial variability, which at present can only be measured from snow-stake measurements.

\section{ACKNOWLEDGEMENTS}

We thank support staff at Halley station for logistical assistance in completing work on Lyddan Ice Rise, and C. S. M. Doake and J. Woodward for valuable discussions. G. R. Bentley and N. Blindow provided reviews that significantly improved the manuscript.

\section{REFERENGES}

Arcone, S. A., A. J. Delaney and W. Tobiasson. 1994. Subsurface radar investigations at the Pegasus glacial-ice runway and Williams Field, McMurdo Station, Antarctica. CRREL Rep. 94-12.

Arcone, S. A., W. Tobiasson and A. J. Delaney. 1995. Ground-penetrating radar investigation of the proposed Dome-CARA tunnel route and utilities at South Pole Station, Antarctica. CRREL Rep. 95-24.

Corr, H. F. J., A. Jenkins, K. W. Nicholls and C. S. M. Doake. 2002. Precise measurement of changes in ice-shelf thickness by phase-sensitive radar to determine basal melt rates. Geophys. Res. Lett., 29(8), 1232. (10.1029/ 2001GL014618.)

Delaney, A. J. and S. A. Arcone. 1995. Detection of crevasses near McMurdo Station, Antarctica, with airborne short-pulse radar. CRREL Spec. Rep. 95-7.

Eisen, O., F. Wilhelms, U. Nixdorf and H. Miller. 2003. Revealing the nature of radar reflections in ice: DEP-based FDTD forward modeling. Geophys. Res. Lett., 30 (5), 1218-1221. (10.1029/2002GL016403.)

Fisher, D. A., R. M. Koerner, W. S. B. Paterson, W. Dansgaard, N. Gundestrup and N. Reeh. 1983. Effect of wind scouring on climatic records from ice-core oxygen-isotope profiles. Nature, 301 (5897), 205-209.

Frezzotti, M., S. Gandolfi and S. Urbini. 2002. Snow megadunes in Antarctica: sedimentary structure and genesis. f. Geophys. Res., 107 (D18), 4344. (10.1029/2001JD000673.

Fujita, S. and 6 others. 1999. Nature of radio-echo layering in the Antarctic ice sheet detected by a two-frequency experiment. 7. Geophys. Res., 104(B6), $13,013-13,024$

Harrison, C. H. 1973. Radio echo sounding of horizontal layers in ice. J. Glaciol., 12(66), 383-397.

King, J. C., P. S. Anderson, D. G. Vaughan, G. W. Mann and S. D. Mobbs. 2004. Wind-borne redistribution of snow across and Antarctic ice rise. 7. Geophys. Res., 109(D11). (10.1029/2003JD004361.)

Kohler, J., J. Moore, M. Kennett, R. Engeset and H. Elvehøy. 1997. Using ground-penetrating radar to image previous years' summer surfaces for mass-balance measurements. Ann. Glaciol., 24, 355-360.

Miners, W. D., E. W. Wolff, J. C. Moore, R. Jacobel and L. Hempel. 2002. Modeling the radio echo reflections inside the ice sheet at Summit, Greenland. 7. Geophys. Res., 107(B8), 2172. (10.1019/2001JB000535.)

Nath, P. C. and D. G. Vaughan. 2000. Sub-surface crevasse formation on ice streams. Filchner-Ronne Ice Shelf Programme Report 13, 40-46.

Nath, P. C. and D. G. Vaughan. 2003. Subsurface crevasse formation in glaciers and ice sheets. f. Geophys. Res., 108(B1), 2020. (10.1029/ 2001JB000453.)

Pälli, A. and 6 others. 2002. Spatial and temporal variability of snow accumulation using ground-penetrating radar and ice cores on a Svalbard glacier. f. Glaciol., 48(162), 417-424.

Paren, J. G. and G. de Q. Robin. 1975. Internal reflections in polar ice sheets. 7. Glaciol., 14(71), 251-259.

Richardson, C. and P. Holmlund. 1999. Spatial variability at shallow snowlayer depths in central Dronning Maud Land, East Antarctica. Ann. Glaciol., 29, 10-16.

Richardson, C., E. Aarholt, S.-E. Hamran, P. Holmlund and E. Isaksson. 1997. Spatial distribution of snow in western Dronning Maud Land, East Antarctica, mapped by a ground-based snow radar. 7. Geophys. Res., 102(B9), 20,343-20,353.

Richardson-Naslund, C. 2004. Spatial characteristics of snow accumulation in Dronning Maud Land, Antarctica. Global and Planetary Change, 42(1-4), 31-44.

Robin, G. de Q., S. Evans andJ.T. Bailey. 1969. Interpretation of radio echo sounding in polar ice sheets. Philos. Trans. R. Soc. London, Ser. A, 265(1166), 437-505. 
Vaughan and others: Imaging firn isochrones across an Antarctic ice rise

Vaughan, D. G., H. F. J. Corr, C. S. M. Doake and E. D. Waddington. 1999. Distortion of isochronous layers in ice revealed by ground-penetrating radar. Nature, $\mathbf{3 9 8}(6725), 323-326$

Woodward, J., P. J. Ashworth, J. L. Best, G. H. Sambrook Smith and C. J.
Simpson. 2003. The use and application of GPR in sandy fluvial environments: methodological considerations. In Bristow, C. S. and H. M. Jol, eds. Ground penetrating radar in sediments. London, Geological Society, 127-142.

MS received 10 November 2003 and accepted in revised form 25 April 2004 